\title{
Effects of a Novel Potent Aldose Reductase Inhibitor, GP-1447, on Aldose Reductase Activity In Vitro and on Diabetic Neuropathy and Cataract Formation in Rats
}

\author{
Naoki Ashizawa, Motoyuki Yoshida, Yoshiko Sugiyama, Nobuhide Akaike, Shigeo Ohbayashi, Tomoji Aotsuka, \\ Naoki Abe, Kanako Fukushima and Akihiro Matsuura \\ Pharmaceutical Research Laboratories, Research Center, Research and Development Division, Grelan Pharmaceutical Co., Ltd., \\ 3-4-3 Sakaecho, Hamura, Tokyo 205, Japan \\ Received July 1, 1996 Accepted November 21, 1996
}

\begin{abstract}
GP-1447 33-[(4,5,7-trifluorobenzothiazol-2-yl)methyl]-5-methylphenylacetic acid\}, a novel aldose reductase (AR) inhibitor, exhibited highly potent and specific inhibition of AR activity from human placenta, human muscle, porcine and rat lens with $\mathrm{IC}_{50}$ values ranging from 3 to $10 \mathrm{nM}$. Lineweaver-Burk plots revealed non-competitive inhibition between DL-glyceraldehyde or $\beta$-NADPH and inhibition of AR by GP-1447. In contrast to epalrestat, AR activity inhibited by GP-1447 did not recover after dialysis for $24 \mathrm{hr}$. Administration of GP-1447 to streptozotocin (STZ)-induced diabetic rats for 5 days beginning 1 week after STZ injection effectively inhibited the accumulation of sorbitol in the sciatic nerve, lens and retina with $\mathrm{ED}_{50}$ values of $0.25,1.6$ and $2.9 \mathrm{mg} / \mathrm{kg} / \mathrm{day}$, respectively. The motor nerve conduction velocity (MCV) in STZ-induced diabetic rats was significantly decreased 4 weeks after the induction of diabetes. Treatment with GP-1447 for the following 2 weeks dose-dependently restored the decreased MCV with an $\mathrm{ED}_{50}$ value of $0.28 \mathrm{mg} / \mathrm{kg} /$ day. Administration of GP-1447 (3 and $15 \mathrm{mg} / \mathrm{kg} /$ day for 12 weeks beginning 3 days after STZ injection) completely prevented cataract formation and was accompanied by marked inhibition of sorbitol accumulation in the lens. Furthermore, partial reversibility of cataract formation and morphological changes of the lens was observed in diabetic rats treated with $15 \mathrm{mg} / \mathrm{kg} /$ day of GP-1447 for 5 weeks beginning 8 weeks after the induction of diabetes. From these results, GP-1447 would be expected to exert potent ameliorating effects on some diabetic complications. Potent inhibition of cataract formation will be one of the characteristics of this compound.
\end{abstract}

Keywords: Aldose reductase inhibitor, Sorbitol, Diabetic neuropathy, Motor nerve conduction velocity, Cataract formation

Aldose reductase (AR), one of the enzymes of the polyol pathway, catalyzes the reduction of glucose to sorbitol, which is subsequently converted to fructose by sorbitol dehydrogenase (SDH). Although the affinity of glucose for AR is quite low under normal conditions (1, 2 ), elevated glucose concentrations, as observed in diabetes mellitus, increases the sorbitol pathway flux $(2,3)$. The enhanced conversion of glucose to sorbitol has been implicated in the pathogenesis of diabetic complications such as neuropathy $(2,4)$, cataract formation $(5,6)$, retinopathy (7-9) and nephropathy $(10,11)$. Recently, in addition to the osmotic stress hypothesis, the redox potential hypothesis was proposed as a theoretical explanation for the involvement of the polyol pathway in diabetic etiology $(12,13)$. The increased flux rate through the polyol pathway implies a higher $\mathrm{NADH} / \mathrm{NAD}^{+}$ratio, leading to the activation of protein kinase- $\mathrm{C}$ via the increased formation of diacylglycerol. Protein kinase-C activation is assumed to be involved in diabetic complications via platelet activation, hyperproliferation of vascular smooth muscle cells and enhancement of the glomerular filtration rate.

A number of AR inhibitors (ARIs) such as epalrestat (14), tolrestat (15), zenaresat (16), SG-210 (17) and SNK860 (18) exhibit some beneficial effects in streptozotocin (STZ)-induced diabetic rats and some are now in clinical trials. The effects of these compounds on cataract formation is inadequate in spite of their potent ameliorating effect on the decreased motor nerve conduction velocity (MCV) in diabetic animals. A possible explanation for 


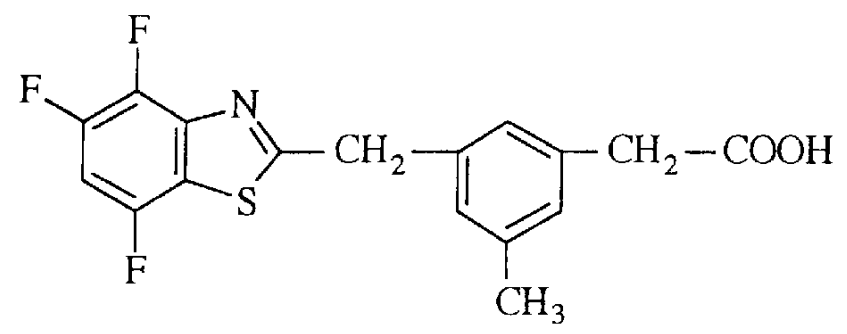

Fig. 1. Chemical structure of GP-1447, 3-[(4,5,7-trifluorobenzothiazol-2-yl)methyl]-5-methylphenylacetic acid.

this is that the effects of the compounds are insufficient in the lens where a much higher accumulation of sorbitol is observed.

Recently, we found a novel ARI, GP-1447\{3-[(4,5,7trifluorobenzothiazol-2-yl)methyl]-5-methylphenyl acetic acid (Fig. 1), that exhibits highly potent AR inhibitory activity in the lens in addition to nerves. In this report, the in vitro biochemical properties of GP-1447 and its effects on diabetic complications, specifically neuropathy and cataract formation in STZ-induced diabetic rats, are described.

\section{MATERIALS AND METHODS}

\section{Care of experimental animals}

Male Sprague-Dawley rats ( 5 weeks of age) were purchased from Japan SLC, Inc. (Hamamatsu). The animals were housed in bracket cages under conditions of controlled temperature $\left(23 \pm 3^{\circ} \mathrm{C}\right)$, humidity $(50 \pm 10 \%)$ and light (8:00-20:00) with food and water freely available. All procedures were carried out in accordance with the guidelines of the Institutional Animal Care and Use Committee.

\section{In vitro studies}

Preparation of $A R$ from porcine and rat lens: AR from porcine and rat lens was prepared as follows (1): All operations were performed at $4^{\circ} \mathrm{C}$. Lenses were homogenized in 3 vol. of cold distilled water with a Teflon homogenizer and centrifuged at $10,000 \times g$ for $15 \mathrm{~min}$ to remove insoluble material. The supernatant was fractionated by $0-40 \%$ saturation with ammonium sulfate and centrifuged at $10,000 \times g$ for $10 \mathrm{~min}$ to remove the precipitate. The supernatant was dialyzed for $6 \mathrm{hr}$ against $50 \mathrm{mM}$ sodium chloride and the dialyzed solution was stored at $-80^{\circ} \mathrm{C}$ prior to use.

Preparation of AR from human placenta: Human placental AR was partially purified according to the method of Clements and Winegrad (19) with minor modifications. After the fractionation of the supernatant of the human placental homogenates by $40-70 \%$ satura- tion with ammonium sulfate, the AR activity was eluted with a linear gradient of 5-200 $\mathrm{mM}$ sodium chloride on a DEAE-cellulose column.

Other enzymes: AR from human muscle was purchased from Wako Pure Chemical Industries, Ltd. (Osaka). Bovine kidney aldehyde reductase (ALR) was prepared using a minor modification of the method of Vander Jagt et al. (20). SDH from sheep liver was obtained from Boehringer Mannheim (Mannheim, FRG).

Determination of $A R$ and $A L R$ activities: With a minor modification of the method of Hayman and Kinoshita (1), AR activity was assayed by the measurement of the absorbance of $\beta-\mathrm{NADPH}$ at $340 \mathrm{~nm}$ at $37^{\circ} \mathrm{C}$ for $2 \mathrm{~min}$ with a Hitachi 7070 auto-analyzer (Tokyo). The assay was carried out in $0.25 \mathrm{ml}$ of $40 \mathrm{mM}$ sodium phosphate buffer (pH 6.2) containing $400 \mathrm{mM}$ lithium sulfate, $0.1 \mathrm{mM} \beta$ NADPH, the enzyme, various concentrations of inhibitors and $3 \mathrm{mM}$ DL-glyceraldehyde as a substrate. The reference blank contained all the above compounds except for the enzyme. All inhibitors were dissolved in dimethylsulfoxide (DMSO) to give a $10 \mathrm{mM}$ solution, and the final concentration of DMSO in the reaction mixture was fixed at $0.1 \%$. The concentrations of inhibitors required for $50 \%$ inhibition of enzyme activity $\left(\mathrm{IC}_{50}\right)$ was estimated from the least-squares regression line of the $\log$ concentration-response curve.

ALR activity was assayed by a similar method to that described above, except for the substrate $(15 \mathrm{mM} \mathrm{D}-$ glucuronic acid instead of DL-glyceraldehyde), the phosphate buffer ( $200 \mathrm{mM}$ phosphate buffer (pH 7.0) instead of $40 \mathrm{mM}$ phosphate buffer ( $\mathrm{pH} 6.2)$ ) and the absence of lithium sulfate (21). SDH activity was measured by monitoring the change in the absorbance of $\beta-\mathrm{NADH}$ at $340 \mathrm{~nm}$ using $400 \mathrm{mM}$ D-fructose as a substrate in 110 $\mathrm{mM}$ triethanolamine buffer $(\mathrm{pH} 7.4)$.

\section{In vivo studies}

Diabetes was induced in rats which had been fasted overnight by a single intravenous injection of $60 \mathrm{mg} / \mathrm{kg}$ body weight of streptozotocin (STZ; Sigma, St. Louis, MO, USA), dissolved in $0.9 \%$ saline immediately before the injection. Normal control rats were injected with saline in a volume of $1 \mathrm{ml} / \mathrm{kg}$ body weight. One week after the STZ injection, blood samples of all rats were collected from the tail vein, and the induction of diabetes was confirmed by the measurement of blood glucose by the hexokinase method. Rats with plasma glucose levels of greater than $300 \mathrm{mg} / \mathrm{dl}$ were regarded as diabetic and grouped, so that the mean body weight and blood glucose level were not significantly different among the groups.

Three in vivo experiments were designed as follows: The first series of experiments was performed to estimate 
the inhibitory effects of GP-1447 on tissue sorbitol accumulation. From 1 week after STZ injection, GP-1447 and other compounds were orally administered once daily for 5 days. Three hours after the final dosing, rats were sacrificed by collecting blood from the abdominal artery under ether anesthesia. The sciatic nerves, lenses and retinas were weighed immediately and frozen at $-80^{\circ} \mathrm{C}$ until used for the measurement of sorbitol content.

The sorbitol content in the tissue was measured by the method of Terashima et al. (14). Briefly, tissues were homogenized in $0.6 \mathrm{ml}$ of $16 \%$ perchloric acid (PCA) and centrifuged. The supernatant was neutralized with $2.0 \mathrm{M}$ $\mathrm{K}_{2} \mathrm{CO}_{3}$ and centrifuged again. The resulting supernatant was used for the sorbitol assay which was carried out enzymatically (22) with an F-kit (D-sorbitol/xylitol, Boehringer Mannheim). The $\mathrm{ED}_{50}$ values of GP-1447 and other test compounds for sorbitol accumulation were obtained by least-squares linear regression.

The second and the third series of experiments were carried out to evaluate the effect of GP-1447 on MCV and cataract formation. In the second series of experiments and the curative study of the third series of experiments, before the administration of the drugs, rats were grouped so that there was no significant difference between the groups in the mean MCV or lens opacity as an index of cataract formation. In the second series of experiments, from 4 weeks after STZ-injection, GP-1447 was orally administered once daily for 2 weeks. The MCV of rat tail was measured under ether anesthesia by the method of Miyoshi and Goto (23) with minor modifications. Caudal temperature was maintained at about $37^{\circ} \mathrm{C}$ by a heater with thermostat (TK-43; Asahi Electric, Tokyo). The longitudinal nerve in the rat tail was stimulated at two points by applying rectangular pulses of $0.1 \mathrm{msec}$ in duration with a voltage sufficient to evoke a supramaximal response. The evoked potentials were amplified and recorded on a Synax ER1100 (NEC San-ei, Tokyo). The MCV $(\mathrm{m} / \mathrm{sec})$ was determined by dividing the distance between two stimulation points by the difference between two latencies of the action potentials. Recovery $\%$ was calculated as follows:

$$
\text { Recovery } \%=([\mathrm{T}]-[\mathrm{D}]) /([\mathrm{N}]-[\mathrm{D}]) \times 100,
$$

where [T] is the MCV of diabetic rats treated with drugs, and $[N]$ and [D] are the MCV of age-matched normal and vehicle-treated diabetic rats, respectively.

In the third series of experiments, the preventive and curative effects of GP-1447 on diabetic cataract formation was examined. In the preventive study, drugs were administered for 12 weeks beginning three days after STZ injection. In the curative study, 8 weeks after STZ injection, drugs were administered to diabetic rats once daily for 5 weeks. The lens opacities were examined once a week with a slit lamp according to the method of Ao et al. (24) after dilating the pupils with Mydrin $P(0.5 \%$ tropicamide and $0.5 \%$ phenylephrine hydrochloride; Santen Pharmaceutical, Osaka). According to the classification of Kador et al. (25) and Chylack et al. (26), the lens opacity score was determined as follows: 0, clear normal lens; 1 , peripheral vesicles; 2 , peripheral vesicles and cortical opacities; 3 , diffuse central opacities; and 4, matured nuclear cataract.

After the final evaluation of cataract development, rats were sacrificed and the sorbitol content in the right lenses was determined according to the method described above. The morphological changes of the left lenses were observed by light microscopy (27). Lenses were fixed with $4 \%$ paraformaldehyde solution buffered at $\mathrm{pH} 7.4$ in $0.1 \mathrm{M}$ phosphate buffer for $48 \mathrm{hr}$. Dehydration was performed in a graded series of ethanol solutions. Tissues were embedded in paraffin and cut into $2-\mu \mathrm{m}$ sections, placed on glass slides, stained with hematoxylin-eosin and studied by light microscopy. The morphological changes in the lens with respect to homogenization of fibers, swelling of fibers and vacuolation were determined. Judging from the degree and diffusion of pathological changes, each lens was scored in a blind study as follows: 0 , no abnormalities; 1 , slight changes; 2 , mild changes; 3 , moderate changes; 4 , severe changes.

\section{Drugs}

GP-1447, epalrestat, zenarestat, tolrestat and SG-210 \{2-[4-(4,5,7-trifluorobenzothiazol-2-yl)methyl-3-oxo-3,4dihydro-2 $H$-1,4-benzothiazin-2-yl]acetic acid $\}$ were synthesized at the Research and Development Division of Grelan Pharmaceutical Co., Ltd. For in vivo experiments, GP-1447 and other ARIs were suspended in the aqueous solution of $0.5 \%$ sodium carboxymethylcellulose.

\section{Statistical analyses}

Results of in vitro and in vivo experiments are expressed as the mean or mean \pm S.E. The significance of the difference between the groups was analyzed by Dunnett's multiple comparison test after one way analysis of variance. The paired $t$-test was used for the analysis of the reversibility of AR inhibition by dialysis. Dunnett's nonparametric multiple comparison test was used for the analysis of scores representing lens opacity and morphological changes in the lens. $P$ values less than 0.05 were regarded as statistically significant.

\section{RESULTS}

\section{Inhibition of aldose reductase and other enzymes}

AR prepared from porcine and rat lens exhibited little ALR activity. As only a small amount of ALR activity 
Table 1. Inhibition of aldose reductase and aldehyde reductase by aldose reductase inhibitors

\begin{tabular}{|c|c|c|c|c|c|}
\hline \multirow{3}{*}{ ARI } & \multicolumn{4}{|c|}{$\begin{array}{c}\mathrm{IC}_{50}(\mathrm{nM}) \\
(95 \% \text { confidence limits })\end{array}$} & \multirow{2}{*}{$\begin{array}{c}\mathrm{IC}_{50}(\mu \mathrm{M}) \\
(95 \% \text { confidence limits }) \\
\text { aldehyde reductase }\end{array}$} \\
\hline & \multicolumn{4}{|c|}{ aldose reductase } & \\
\hline & HP & $\mathrm{HM}$ & PL & RL & BK \\
\hline GP-1447 & $\begin{array}{c}3.1 \\
(2.1-4.1)\end{array}$ & $\begin{array}{c}5.9 \\
(4.6-7.2)\end{array}$ & $\begin{array}{c}9.6 \\
(8.1-11)\end{array}$ & $\begin{array}{c}6.5 \\
(5.3-7.9)\end{array}$ & $>100$ \\
\hline Epalrestat & $\begin{array}{c}32 \\
(23-45)\end{array}$ & $\begin{array}{c}35 \\
(27-45)\end{array}$ & $\begin{array}{c}31 \\
(25-38)\end{array}$ & $\begin{array}{c}37 \\
(28-47)\end{array}$ & $\begin{array}{c}3.8 \\
(3.0-4.9)\end{array}$ \\
\hline Zenarestat & $\begin{array}{c}6.6 \\
(5.2-8.1)\end{array}$ & $\begin{array}{c}8.8 \\
(7.4-10)\end{array}$ & $\begin{array}{c}12 \\
(9.9-14)\end{array}$ & $\begin{array}{c}7.3 \\
(6.1-8.6)\end{array}$ & $\begin{array}{c}11 \\
(8.1-14)\end{array}$ \\
\hline Tolrestat & $\begin{array}{c}12 \\
(9.8-15)\end{array}$ & $\begin{array}{c}14 \\
(11-17)\end{array}$ & $\begin{array}{c}16 \\
(13-20)\end{array}$ & $\begin{array}{c}13 \\
(10-15)\end{array}$ & $\begin{array}{c}1.0 \\
(0.77-1.3)\end{array}$ \\
\hline SG-210 & $\begin{array}{c}6.7 \\
(5.5-8.0)\end{array}$ & $\begin{array}{c}6.6 \\
(5.5-7.8)\end{array}$ & $\begin{array}{c}11 \\
(9.0-13)\end{array}$ & $\begin{array}{c}7.7 \\
(6.5-9.1)\end{array}$ & $>100$ \\
\hline
\end{tabular}

ARI: aldose reductase inhibitor, HP: human placenta, HM: human muscle, PL: porcine lens, RL: rat lens, BK: bovine kidney.

was detected in AR from human placenta, its effect on the measurement of AR activity was negligible.

The inhibitory effects of GP-1447, epalrestat, zenarestat, tolrestat and SG-210 on $\mathrm{AR}$ from various sources and on ALR are summarized in Table 1. The $\mathrm{IC}_{50}$ values of GP-1447 ranged from $3.1 \mathrm{nM}$ for human placenta AR to $9.6 \mathrm{nM}$ for porcine lens AR. GP- 1447 appeared to be a highly potent inhibitor of $A R$ from four sources and was approximately five times as potent an inhibitor as epalrestat and twice as potent as tolrestat. In contrast to epalrestat, zenarestat and tolrestat, GP-1447 exhibited almost no inhibition of ALR, which is the most closely related enzyme to AR, suggesting that the compound possesses highly specific inhibition against AR. No compound showed more than $50 \%$ inhibition against $\mathrm{SDH}$ at $100 \mu \mathrm{M}$. GP-1447 exhibited no inhibitory effect on SDH at $100 \mu \mathrm{M}$. Enzyme kinetic studies using porcine lens AR revealed that GP-1447 at concentrations of 7.5 and $15 \mathrm{nM}$ exhibited noncompetitive inhibition with glyceraldehyde or $3-\mathrm{NADPH}$ in Lineweaver-Burk plots as apparent convergence of the $K_{m}$ values was observed (Fig. 2).

Table 2 demonstrates the reversibility of AR inhibition by dialysis. After AR was dialyzed against buffer with $1 \mathrm{mM}$ dithiothreitol for $24 \mathrm{hr}$, AR activity decreased to $63 \pm 2 \%$ of activity before dialysis. In the absence of dithiothreitol, only $34 \pm 2 \%$ of AR activity remained. The inhibitory effect of GP-1447 remained after the AR treated with GP-1447 was dialyzed against buffer with or without $1 \mathrm{mM}$ dithiothreitol. In contrast, inhibition by epalrestat was completely reversible. The decrease in AR activity after dialysis in the absence of dithiothreitol was reversed by the addition of epalrestat to AR, since the activity increased by $34.9 \pm 5.4 \%$ (Table 2 ). a)

\section{[1/A A340]}

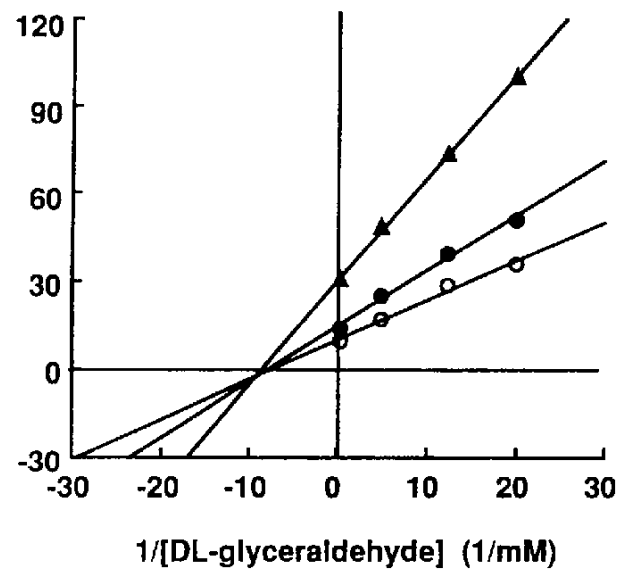

b)

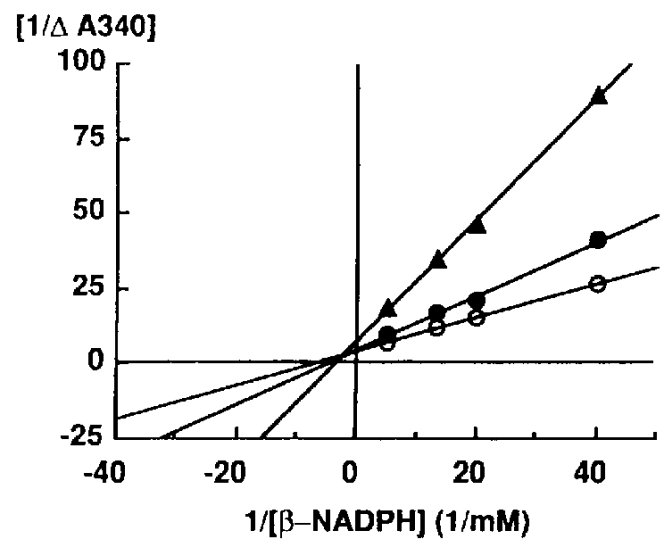

Fig. 2. Effect of GP-1447 on the Lineweaver-Burk plot of porcine lens aldose reductase activity with DL-glyceraldehyde as substrate. The ordinate represents the reciprocal of initial velocity expressed as the change in optical density per $2 \mathrm{~min}$. The abscissa represents the reciprocal of Di-glyceraldehyde concentrations ranging between 0.05 and $3 \mathrm{mM}$ (a) or the reciprocal of $\beta$-NADPH concentrations ranging between 0.025 and $0.2 \mathrm{mM}$ (b). $7.5 \mathrm{nM}$; $\Delta, 15 \mathrm{nM} \mathrm{GP}-1447$; and $Q$ uninhibited control. 
Table 2. Effect of dialysis on the inhibition of rat lens aldose reductase by GP-1447 and epalrestat

\begin{tabular}{lcccccc}
\hline & & & \multicolumn{3}{c}{ Inhibition $\%$} \\
\cline { 3 - 6 } & & \multicolumn{2}{c}{$\begin{array}{c}\text { Dithiothreitol }(-) \\
\text { before dialysis }\end{array}$} & after dialysis & before dialysis & after dialysis \\
\hline \multirow{2}{*}{ GP-1447 } & $(40 \mathrm{nM})$ & $37.4 \pm 1.3$ & $49.0 \pm 5.4$ & $41.9 \pm 9.1$ & $39.2 \pm 9.1$ \\
Epalrestat & $(200 \mathrm{nM})$ & $43.7 \pm 1.0$ & $-34.9 \pm 5.4^{* *}$ & $39.4 \pm 1.8$ & $1.6 \pm 1.4^{* *}$ \\
\hline
\end{tabular}

Rat lens aldose reductase was incubated with $40 \mathrm{nM}$ of GP-1447 or $200 \mathrm{nM}$ of epalrestat at $37^{\circ} \mathrm{C}$ for $30 \mathrm{~min}$, and then dialyzed against $10 \mathrm{mM}$ phosphate buffer $(\mathrm{pH} 6.2)$ with or without $1 \mathrm{mM}$ dithiothreitol at room temperature for 24 hr. Values are the mean \pm S.E. of 4 experiments. ${ }^{* *} \mathrm{P}<0.01$, compared with the value before dialysis by the paired t-test.

Effects of treatment with GP-1447 on body weight gain and blood glucose in vivo

In the first series of experiments, body weight and blood glucose of untreated STZ-induced diabetic rats were $210 \pm 8.1 \mathrm{~g}$ and $542 \pm 27 \mathrm{mg} / \mathrm{dl}$, respectively. Treatment with GP-1447 for 5 days had no significant effect on body weight gain and blood glucose levels in STZinduced diabetic rats. Similar results were obtained in the second and the third series of experiments.

\section{Effects on sorbitol accumulation in various tissues of diabetic rats in vivo}

The sorbitol content in the vehicle-treated diabetic rats was $0.55 \pm 0.09 \mu \mathrm{mol} / \mathrm{g}$ for the sciatic nerves, $31 \pm 1.0$ $\mu \mathrm{mol} / \mathrm{g}$ for the lenses and $0.49 \pm 0.14 \mu \mathrm{mol} / \mathrm{g}$ for the retinas. Administration of GP-1447 resulted in potent inhibition of sorbitol accumulation in these tissues in a dosedependent manner (Table 3). The $\mathrm{ED}_{50}$ values were 0.25 , 1.6 and $2.9 \mathrm{mg} / \mathrm{kg} / \mathrm{day}$ in the sciatic nerves, lenses and retinas, respectively. The respective $\mathrm{ED}_{50}$ values of SG210 on the sciatic nerves and lenses were 1.8 and 14 $\mathrm{mg} / \mathrm{kg} / \mathrm{day}$. Zenarestat, at a dose of $30 \mathrm{mg} / \mathrm{kg} / \mathrm{day}$, inhibited sorbitol accumulation by $76 \%$ in the sciatic nerves and by $21 \%$ in the lenses. Epalrestat, at the same dose, exhibited only $36 \%$ and $17 \%$ inhibition in the sciatic nerves and lenses, respectively. These results indicate that GP-1447 is about eight times more potent than SG-210 in inhibiting sorbitol accumulation in both the sciatic nerves and lenses.

\section{Effects on the reduced $M C V$ in diabetic rats}

At 4 weeks after STZ-injection, the MCV in STZinduced diabetic rats was significantly lower than that in normal control rats. The values for the two groups were $32.4 \pm 0.6 \mathrm{~m} / \mathrm{sec}(\mathrm{n}=7)$ and $29.1 \pm 0.6 \mathrm{~m} / \mathrm{sec} \quad(\mathrm{n}=6)$, respectively. After the final administration of GP-1447 (6 weeks after STZ injection), a similar difference between the normal control rats and untreated STZ-induced diabetic rats was still observed. The values for the two groups were $33.7 \pm 0.6$ and $28.8 \pm 1.1 \mathrm{~m} / \mathrm{sec}$, respectively. As shown in Fig. 3, treatment with GP-1447 for 2 weeks ameliorated the reduced $\mathrm{MCV}$ in a dose-dependent manner with almost complete recovery of the MCV to the control level observed at the dose of $3 \mathrm{mg} / \mathrm{kg} / \mathrm{day}$. The

Table 3. Inhibitory effect of GP-1447 on sorbitol accumulation in the various tissues of streptozotocin (STZ)-induced diabetic rats

\begin{tabular}{|c|c|c|c|c|}
\hline \multirow{2}{*}{$\begin{array}{l}\text { Animal } \\
\text { group }\end{array}$} & \multirow{2}{*}{$\begin{array}{c}\text { Dose } \\
(\mathrm{mg} / \mathrm{kg} / \text { day })\end{array}$} & \multicolumn{3}{|c|}{ Inhibition $\%$} \\
\hline & & sciatic nerve & lens & retina \\
\hline Diabetic & 0.1 & $21.6 \pm 7.8$ & & \\
\hline \multirow[t]{6}{*}{$+\mathrm{GP}-1447$} & 0.3 & $25.5 \pm 11.2$ & & \\
\hline & 1 & $100.0 \pm 0.0^{* *}$ & $35.7 \pm 8.1$ & $-61.3 \pm 92.2$ \\
\hline & 3 & $98.3 \pm 1.7^{* *}$ & $74.5 \pm 8.4^{* *}$ & $58.2 \pm 17.9$ \\
\hline & 10 & $100.0 \pm 0.0^{* *}$ & $60.1 \pm 8.3^{* * *}$ & $93.6 \pm 6.4^{*}$ \\
\hline & & \multicolumn{3}{|c|}{$\mathrm{ED}_{50}(\mathrm{mg} / \mathrm{kg} /$ day $)$} \\
\hline & & 0.25 & 1.6 & 2.9 \\
\hline
\end{tabular}

From 7 days after STZ injection, GP-1447 was orally administered to diabetic rats once daily for 5 days. Values are the mean \pm S.E. of $4-5$ rats. ${ }^{*} \mathrm{P}<0.05,{ }^{* *} \mathrm{P}<0.01$, compared with the vehicle-treated diabetic group by Dunnett's multiple comparison test. 


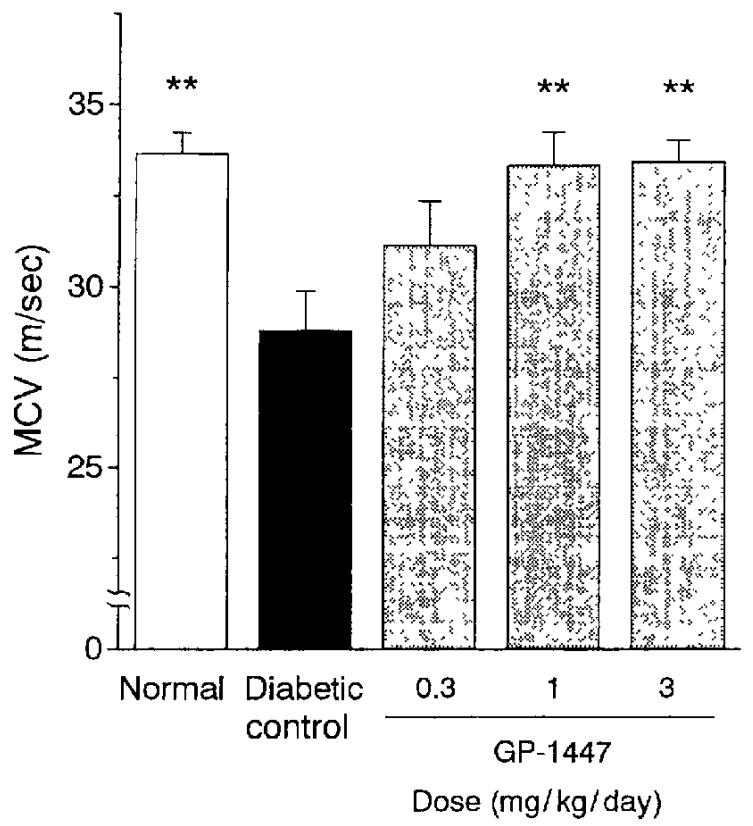

Fig. 3. Curative effect of GP-1447 on reduced motor nerve conduction velocity (MCV) in STZ-induced diabetic rats. From 4 weeks after STZ injection, GP-1447 was orally administered once daily for 2 weeks. Values are the mean \pm S.E., $n=5-7$. ${ }^{* *} \mathrm{P}<0.01$, compared with the untreated diabetic group by Dunnett's multiple comparison test.

$\mathrm{ED}_{50}$ values for the recovery of $\mathrm{MCV}$ was 0.28 $\mathrm{mg} / \mathrm{kg} /$ day, while $0.24 \mathrm{mg} / \mathrm{kg} /$ day was required for $50 \%$ inhibition of sorbitol accumulation in the sciatic nerves. The improvement of the MCV after treatment with GP1447 correlated with the sorbitol content in the sciatic nerves (Fig. 4; $\mathrm{r}=-0.529, \mathrm{P}<0.01$ ). The $\mathrm{ED}_{50}$ value of SG-210 was $6.5 \mathrm{mg} / \mathrm{kg} /$ day for the restoration of $\mathrm{MCV}$. Zenarestat increased the reduced MCV by $54 \%$ at a dose of $30 \mathrm{mg} / \mathrm{kg} /$ day, while epalrestat decreased the $\mathrm{MCV}$ in diabetic rats by $4 \%$ at a dose of $10 \mathrm{mg} / \mathrm{kg} /$ day.

\section{Effects on cataract formation of STZ-induced diabetic rats}

The progression of lens opacity in untreated STZinduced diabetic rats was observed from 2 weeks after STZ-injection until the end of the study using slit lamp microscopy (Fig. 5a). At 12 weeks, all rats showed lens opacity in which more than $40 \%$ lenses were classed at score 4 . The results observed for the progression of lens opacity in this study are in general agreement with the results respected in a previous study (24); we therefore conclude that our determination of lens opacity gives accurate information on cataract formation. Oral administration of GP-1447 at doses of 3 and $15 \mathrm{mg} / \mathrm{kg} /$ day and of SG-210 at $15 \mathrm{mg} / \mathrm{kg} /$ day beginning three days after STZ injection completely prevented cataract formation;

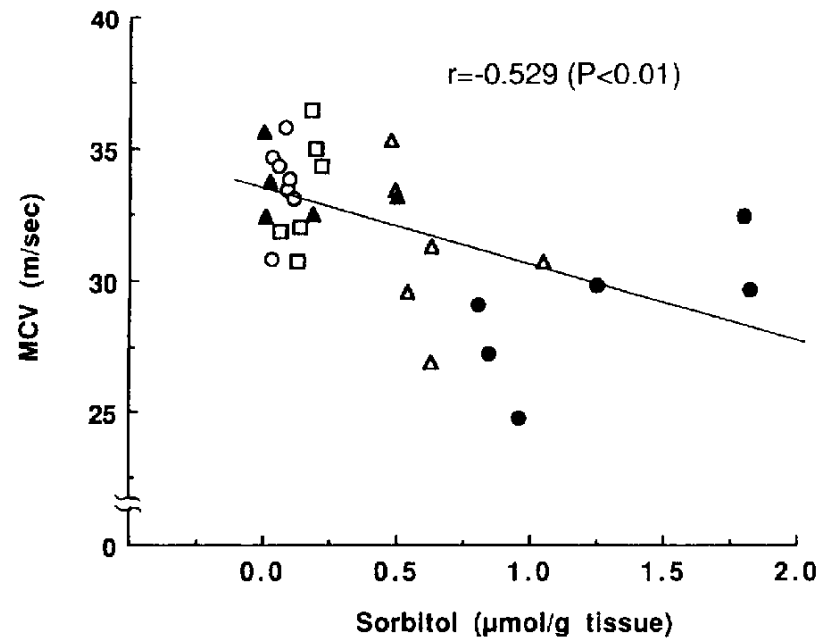

Fig. 4. Correlation between motor nerve conduction velocity (MCV) and sciatic nerve sorbitol content in normal control rats $(\bigcirc)$; vehicle-treated diabetic rats $(O)$; diabetic rats treated with GP-1447 at $0.3 \mathrm{mg} / \mathrm{kg} /$ day $(\triangle), 1 \mathrm{mg} / \mathrm{kg} /$ day $(\square)$ and $3 \mathrm{mg} / \mathrm{kg} /$ day $(\Delta)$. Total number of data points is 30 .

i.e., the lens opacity score in these groups was 0 during the observation period and was similar to that of normal lenses. In diabetic rats treated with zenarestat at a dose of $15 \mathrm{mg} / \mathrm{kg} / \mathrm{day}$, the progression of lens opacity was delayed compared with untreated STZ-induced diabetic rats. However, abrupt lens opacity was observed at 8 weeks, followed by linear development to 12 weeks. At 12 weeks after STZ-injection, only 2 of 12 lenses of the zenarestat-treated rats had shown no cataract formation (score 0 ). Figure $5 \mathrm{~b}$ shows the sorbitol content in the lenses after the observation; the results confirm the potent inhibitory effect of GP-1447, which exhibited almost complete inhibition at $15 \mathrm{mg} / \mathrm{kg} / \mathrm{day}$. GP -1447 was estimated to be five times more potent than SG-210 at inhibiting sorbitol accumulation, as the inhibitory effect of GP-1447 at a dose of $3 \mathrm{mg} / \mathrm{kg} /$ day was similar to that of SG-210 at $15 \mathrm{mg} / \mathrm{kg} /$ day. Zenarestat $(15 \mathrm{mg} / \mathrm{kg} /$ day $)$ showed only $34 \%$ inhibition against sorbitol accumulation.

In addition to their preventive effects, the curative effects of ARIs on cataracts were examined by the oral administration of the drugs for 5 weeks beginning 8 weeks after the induction of diabetes. The mean lens opacity score in diabetic rats was approximately 2.0 just before the treatment with ARIs. As shown in Fig. 6, the score of untreated STZ-induced diabetic rats increased by $0.33 \pm 0.19$ during 5 weeks. In contrast to the preventive study, administration of zenarestat was ineffective in the progression of cataract formation. Both SG-210 and GP1447 at the dose of $15 \mathrm{mg} / \mathrm{kg} /$ day not only inhibited the increase but decreased the lens opacity score. GP-1447 
had a more potent ameliorating effect on cataracts than SG-210, since the decrease in the opacity score by treatment with GP-1447 was $0.61 \pm 0.23$, and it was significantly different from the diabetic control. However, at a dose of $3 \mathrm{mg} / \mathrm{kg} /$ day, GP-1447 failed to decrease the score. Thus, GP-1447 exhibited both curative and preventive effects on cataract formation in STZ-induced diabetic rats.

The lenses of the rats used in the curative study were evaluated by light microscopy. Lenses obtained from STZ-induced diabetic rats showed apparent homogenization of fibers, swelling of fibers and vacuolation in marked contrast to the normal control rats (Fig. 7, Table 4). Treatment with zenarestat failed to affect the frequency of the morphological changes described above.
$\mathrm{GP}-1447$, at $3 \mathrm{mg} / \mathrm{kg} / \mathrm{day}$, tended to inhibit the swelling of fibers and vacuolation; i.e., the score decreased to $1.9 \pm 0.2$ and $1.1 \pm 0.4$, respectively. However, treatment with the same dose was ineffective in reducing the homogenization of fibers. GP-1447 and SG-210, at a dose of $15 \mathrm{mg} / \mathrm{kg} /$ day, exhibited a more potent ameliorating effect than zenarestat $(15 \mathrm{mg} / \mathrm{kg} /$ day $)$ or GP-1447 (3 $\mathrm{mg} / \mathrm{kg} /$ day). The curative effect of GP-1447 on the morphological changes in diabetic rats is considered to be equivalent to that of SG-210. However, there remained considerable morphological changes in the lenses even after treatment with these two ARIs at $15 \mathrm{mg} / \mathrm{kg} /$ day. The treatment with ARIs produced no significant decrease in the score for pathological changes.

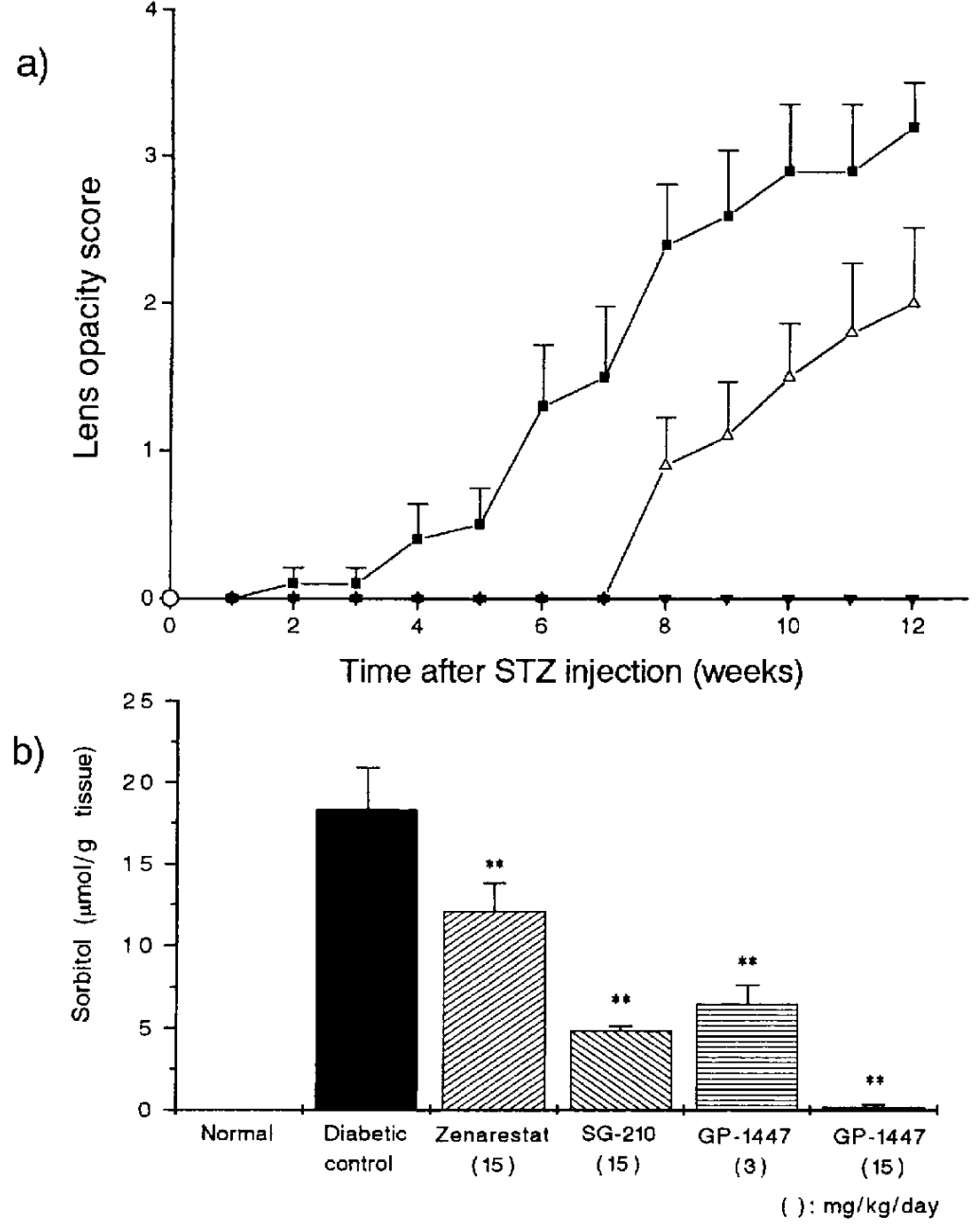

Fig. 5. Effects of various ARIs on cataract formation and sorbitol accumulation in the lenses of STZ-induced diabetic rats. a: Preventive effects of various ARIs on cataract formation in diabetic rats. Rats injected with STZ (60 mg/ $\mathrm{kg}$, i.v.) were treated with vehicle $(\square)$ or ARIs at $3 \mathrm{mg} / \mathrm{kg} /$ day $(\mathrm{GP} 1447, \nabla$ ) or $15 \mathrm{mg} / \mathrm{kg} /$ day (zenarestat, $\triangle ; \mathrm{SG}-210, \square ; \mathrm{GP}-1447,0$ ) for 12 weeks. Lens opacity was determined (score 0 to 4 ) by using a slit lamp after dilating the pupils $(n=5-10)$. No cataract formation was observed in normal control rats $(O)$ and diabetic rats treated with GP- 1447 at doses of 3 and $15 \mathrm{mg} / \mathrm{kg} / \mathrm{day}$ or SG-210. b: Sorbitol accumulation in the lenses after the observation. ${ }^{* *} \mathrm{P}<0.01$, compared with the diabetic-control by Dunnett's multiple comparison test. 


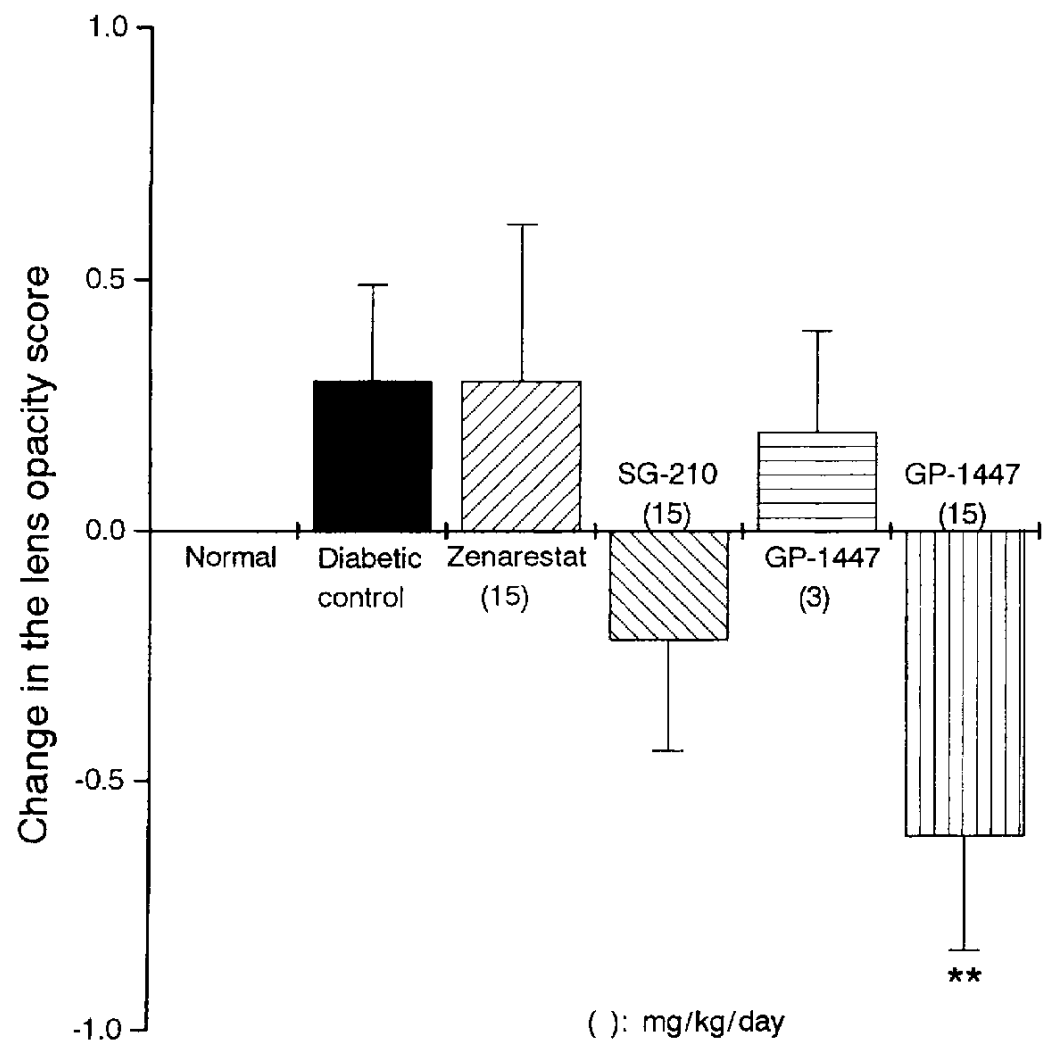

Fig. 6. Curative effects of various ARIs on the cataracts in diabetic rats. Values represent the change in lens opacity score during the treatment with ARIs. From 8 weeks after STZ-injection, ARIs were orally administered at the dose of $3 \mathrm{mg} / \mathrm{kg} / \mathrm{day}$ (GP-1447) or $15 \mathrm{mg} / \mathrm{kg} /$ day (zenarestat, SG-210, GP-1447) once daily for 5 weeks. Lens opacity was determined (score 0 to 4 ) by using a slit lamp after dilating the pupils $(n=6-10)$. The mean lens opacity score in diabetic rats was apploximately 2.0 just before the treatment with ARIs. Three out of nine rats in the zenarestat-treated group died during the 5-week administration. ${ }^{* *} \mathbf{P}<0.01$, compared with the diabetic control by Dunnett's non-parametric multiple comparison test.

Table 4. Curative effects of various ARIs on the histological changes in diabetic rat lens

\begin{tabular}{lrrrr}
\hline & & \multicolumn{3}{c}{ Score of morphological changes } \\
\cline { 3 - 5 } & & homogenization of fibers & swelling of fibers & vacuolation \\
\hline Normal & & $0.2 \pm 0.2^{* *}$ & $0.1 \pm 0.1^{* *}$ & $0.0 \pm 0.0^{* * *}$ \\
Diabetic control & & $2.3 \pm 0.4$ & $2.8 \pm 0.2$ & $2.0 \pm 0.3$ \\
Zenarestat & $(15)$ & $3.3 \pm 0.3$ & $2.7 \pm 0.2$ & $1.5 \pm 0.5$ \\
SG-210 & $(15)$ & $2.1 \pm 0.4$ & $1.9 \pm 0.2$ & $1.0 \pm 0.3$ \\
GP-1447 & $(3)$ & $2.8 \pm 0.3$ & $1.9 \pm 0.2$ & $1.1 \pm 0.4$ \\
GP-1447 & $(15)$ & $2.0 \pm 0.4$ & $2.1 \pm 0.3$ & $1.0 \pm 0.4$ \\
\hline
\end{tabular}

( ): $\mathrm{mg} / \mathrm{kg} /$ day. Values are the mean \pm S.E. of scores (from 0 to 4 ) of morphological changes in the lenses $(n=6-10)$. From 8 weeks after STZ injection, ARIs were orally administered at the dose of 3 $\mathrm{mg} / \mathrm{kg} /$ day (GP-1447) or $15 \mathrm{mg} / \mathrm{kg} /$ day (zenarestat, SG-210, GP-1447) once daily for 5 weeks. Lens tissues stained with hematoxylin-eosin were studied using light microscopy, ${ }^{* *} \mathrm{P}<0.01$, compared with the vehicle-treated diabetic group by Dunnett's non-parametric multiple comparison test.

\section{DISCUSSION}

GP-1447 inhibited AR isolated and partially purified from human, porcine and rat sources with $\mathrm{IC}_{50}$ values ranging from 3 to $10 \mathrm{nM}$; these values indicate that GP-1447 is slightly more potent than the other ARIs. In in vivo studies, the inhibitory effects of GP-1447 were significantly more potent than other ARIs including 
a

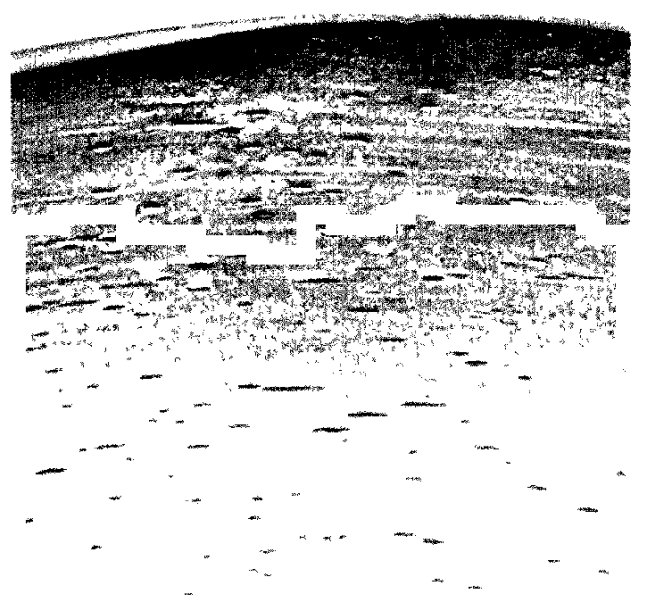

c

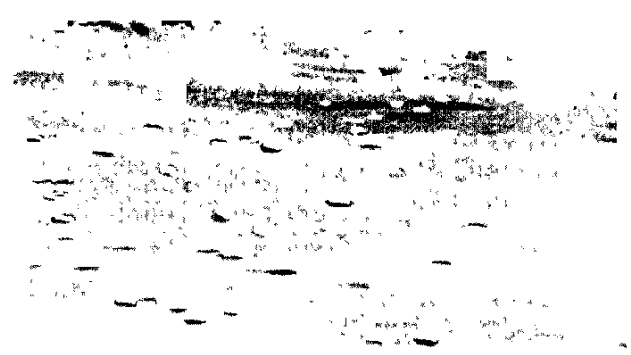

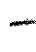

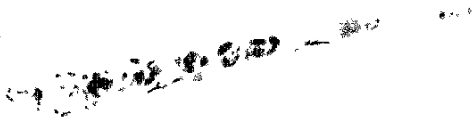

Fig. 7. Light microscope photographs of the lens tissues of normal rats (a) and STZ-induced diabetic rats (b, c, d). The rats were examined at 13 weeks after STZ injection (hematoxylin-eosin staining, $\times 50$ in (a), (b), (c) and $\times 100$ in (d)). Homogenization of fibers (b) and swelling of fibers (c) and vacuolation in the lens tissue (d) indicated by arrows were observed in untreated STZ-induced diabetic rats.

zenarestat and SG-210. Treatment of STZ-induced diabetic rats with GP-1447 for 5 days reduced the elevated sorbitol levels in the sciatic nerves, lenses and retinas in a dose-dependent manner. The comparison of $E D_{50}$ values of ARIs in sorbitol accumulation indicated that GP-1447 was approximately eight times more potent than SG-210 in spite of having a similar $\mathrm{IC}_{50}$ value for rat lens $\mathrm{AR}$ in vitro. This discrepancy may be due to the differences between these compounds with respect to distribution after oral administration or tissue penetration. The elimination of GP-1447 from plasma is fast with a $t_{1 / 2}$ value of less than $1 \mathrm{hr}$ after oral administration in rats $(\mathbf{H}$. Narihata et al., unpublished data). From the comparison between the two ARIs, i.e., AD-5467 and CT-112, the hydrophilic compound AD-5467 was suggested to be more easily transferred to the water-soluble fraction of the lens cells where AR is located $(28,29)$, leading to the efficient attack of the target enzymes in the lens. The octanol/water (pH 7.5 phosphate buffer) partition coefficient is 7.0 for zenarestat, 24.1 for SG-210 and 59.8 for GP-1447, indicating that GP-1447 is more lipophilic than the other two compounds. The potent inhibitory effect of GP-1447 on sorbitol accumulation in the lens is therefore not due to the hydrophilic/lipophilic properties of the compound. 
The inhibition of AR activity by GP-1447 was apparently irreversible in contrast with the inhibition by epalrestat. Although AR activity inhibited by GP-1447 may recover after dialysis for a longer period, this characteristic of this compound may, at least partially, contribute to its potent effects in vivo. The decrease in AR activity by dialysis was partially inhibited when AR was dialyzed against buffer containing dithiothreitol, suggesting the sulfhydryl requirement of AR (1). Addition of epalrestat to AR reversed the decrease in AR activity by dialysis in the absence of dithiothreitol. Binding of epalrestat to AR at the initiation of dialysis may stabilize the enzyme, leading to the partial preservation of AR activity during dialysis.

To evaluate the efficacy of GP-1447 on diabetic complications, we investigated its effect on the reduced $\mathrm{MCV}$ and the cataract formation using STZ-induced diabetic rats. Treatment with GP-1447 dose-dependently ameliorated the slowed $\mathrm{MCV}$ with an $\mathrm{ED}_{50}$ value of 0.28 $\mathrm{mg} / \mathrm{kg} / \mathrm{day}$, indicating that this compound is approximately twenty times more potent than SG-210 in restoring the reduced MCV. In contrast to our results, SG-210 has been reported to recover the reduced $\mathrm{MCV}$, the $\mathrm{ED}_{50}$ value being $0.5 \mathrm{mg} / \mathrm{kg} /$ day (17). The reason for this discrepancy is unclear, but may be due to the different methods used. A slight elevation in the surface temperature of the rat tails leads to an increase in the MCV as reported (23), and therefore the difference in the caudal temperature between the two experiments may affect the efficacy of the drug. Since some correlation was observed between the sorbitol level in the sciatic nerves and MCV in the present study as observed in the experiments using TAT (30) and SG-210 (17), abnormalities of glucose metabolism due to hyperglycemia in the tissue is considered to be involved in the nerve dysfunction. The accumulation of sorbitol per se or an elevated NADH $/ \mathrm{NAD}^{+}$ratio due to the increased flux rates through the polyol pathway (13) in the nerve tissue has been suggested to be involved in the decrease of the $\mathrm{MCV}$. The increase in cyclic AMP content in the nerve tissues is suggested as one of the factors to ameliorating the reduced $\mathrm{MCV}$ in diabetic rats $(31,32)$. We observed that many ARIs possess inhibitory effects against phosphodiesterase, an inactivating enzyme of cyclic AMP. The $\mathrm{IC}_{50}$ values of epalrestat, SG-210 and GP-1447 for phosphodiesterase were 83,30 and $36 \mu \mathrm{M}$, respectively. However, GP-1447 and SG-210 did not have any apparent effect on the reduced cyclic AMP content in the sciatic nerves of STZ-induced diabetic rats at the dose employed in the experiment on the MCV (N. Ashizawa et al., unpublished data). Thus, it is considered that cyclic AMP alone in the sciatic nerves is not a prerequisite for the MCV. In contrast, nerve blood flow in which cyclic AMP might be involved as one of the factors is reported to decrease in the diabetic rats and may be an important factor for restoring the $\mathrm{MCV}$. During the last few decades, attention has been directed towards alterations in the blood and the role of altered blood elements in the pathogenesis of diabetic complications. Thus, we are currently evaluating the effects of GP-1447 on the blood stream and blood rheological properties including the sciatic nerve blood flow, erythrocyte deformability and platelet aggregation using STZinduced diabetic rats. These results will be described elsewhere.

Oral treatment with GP-1447 reduced the lens sorbitol level by its highly potent inhibition of polyol production and consequently inhibited morphological changes in the lens and prevented the progression of cataract formation. GP-1447, at doses of 3 and $15 \mathrm{mg} / \mathrm{kg} / \mathrm{day}$, completely prevented cataract formation. Zenarestat was partially effective at $15 \mathrm{mg} / \mathrm{kg} / \mathrm{day}$, i.e., it only delayed the cataract formation. Further evaluation revealed that treatment with GP-1447 after cataract formation reversed the diabetic cataract as evidenced by the decrease in lens opacity score (Fig. 6) and by the partial recovery of histological changes in the microscopic determinations (Table 4). Although some ARIs are reported to exhibit the preventive effects against cataracts, only a few reports (33, 34) describe the curative effects of ARIs. Sorbinil partially reversed the very early morphological signs such as fiber hydration or granulation of diabetic (33) and sugar (34) cataracts. When treatment of diabetic rats with sorbinil was started 16 days after STZ injection, the lenses remained transparent, and only partial vacuolation of the anterior cortex of the lens was observed. In the present study, oral administration of GP-1447 subsequent to score 2 cataractogenesis in diabetic rats promoted a process of reversal, indicating that GP-1447 possesses potent inhibitory effects even in conditions in which peripheral vesicles and cortical opacities have been already formed. This property of GP-1447, i.e., inhibition of cataract formation, discriminates it from the other ARIs.

In the experiment of the prophylactic effect on cataract formation, treatment with SG- 210 at $15 \mathrm{mg} / \mathrm{kg} /$ day or GP -1447 at $3 \mathrm{mg} / \mathrm{kg} /$ day completely prevented cataract formation in spite of only partial inhibition of sorbitol accumulation. The formation of cataracts may be very sensitive to the amount of sorbitol accumulated in the lens. The inhibition of sorbitol accumulation by $70 \%$ may be sufficient to inhibit cataract formation at least during the observation period in the present study, although it is possible that delayed formation of cataracts may occur in a longer experiment. With the progression of intense diabetic cataracts, the disruption and disintegration of lenticular fibers accompanied with leakage and loss of metabolites were observed (35). Thus, in the lenses treat- 
ed with SG-210 and the lower dose of GP-1447, because of the inhibition of lens tissue disruption, a passive efflux of materials including sorbitol might be inhibited, leading to the preservation of remaining sorbitol in the lens tissue. This hypothesis may explain why only a smaller accumulation of lens sorbitol in the above two groups resulted in the complete inhibition of cataract formation in contrast to the zenarestat-treated group, in which severe morphological changes in the lens tissue was observed (N. Ashizawa et al., unpublished data).

Since the antioxidant butylated hydroxytoluene and the cysteine protease inhibitor E64 inhibited hyperglycemiainduced biochemical change of cultured bovine lens, it is suggested that sugar cataractogenesis is a multifactorial process in which other mechanisms are also involved besides the polyol pathway mechanism (36). In galactose cataracts, activation of calpain, a cysteine protease, and proteolysis of $\alpha$ - and $\beta$-crystallins was inhibited by SG210 (37), suggesting that proteolysis by calpain is an underlying mechanism for the formation of sugar cataracts. Testing a combination of a potent ARI and calpain inhibitor will provide further information. GP-1447, as a potent inhibitor of cataract formation, may be a useful tool to clarify the pathogenesis of cataracts.

In conclusion, GP-1447, a highly specific ARI with no asymmetric carbon atom, exhibited highly potent AR inhibition both in vitro and in vivo. The compound ameliorated the reduced $\mathrm{MCV}$ and cataract formation accompanied by a distinct decrease in the sorbitol content in the target tissues of diabetic rats. It is one of the most potent ARIs with an acetic acid moiety. GP-1447 would be expected to be a useful ARI for the treatment of diabetic complications and can be discriminated from other ARIs by its potent inhibitory effect on cataract formation, and its curative effect on cataracts.

\footnotetext{
Acknowledgment

We would like to thank Dr. Hugh McMahon for his critical reading of the manuscript.
}

\section{REFERENCES}

1 Hayman S and Kinoshita JH: Isolation and properties of lens aldose reductase. J Biol Chem 240, 877-882 (1965)

2 Gabbay $\mathrm{KH}$ : The sorbitol pathway and the complications of diabetes. N Engl J Med 288, 831-836 (1973)

3 Ghahary A, Luo JM, Gong YW, Chakrabarti S, Sima AA and Murply LJ: Increased renal aldose reductase activity, immunoreactivity and mRNA in streptozotocin-induced diabetic rats. Diabetes 38, $1067-1071$ (1989)

4 Gabbay KH, Merola LO and Field RA: Sorbitol pathway: Presence in nerve and cord with substrate accumulation in diabetes. Science 151, 209-210 (1966)

5 Heyningen RV: Formation of polyols by the lens of the rat with 'sugar' cataract. Nature 184, 194-195 (1959)

6 Varma SD, Schocket SS and Richards RD: Implications of aldose reductase in cataracts in human diabetes. Invest Ophthalmol Vis Sci 18, 237-241 (1979)

7 Akagi Y, Kador PF, Kuwabara T and Kinoshita JH: Aldose reductase localization in human retinal mural cells. Invest Ophthalmol Vis Sci 24, 1516-1519 (1983)

8 Schofield PJ and Gould NJ: Initial changes in the free carbohydrate profile of rat lens and retina following streptozotocininduced diabetes. Mol Cell Biochem 28, 17-21 (1979)

9 Engerman RL and Kern TS: Experimental galactosemia produces diabetic-like retinopathy. Diabetes 33, 97-100 (1984)

10 Cohen MP: Aldose reductase, glomerular metabolism, and diabetic neuropathy. Metabolism 35, Supp 1, 55-59 (1986)

11 Beyer-Mears A: The polyol pathway, Sorbinil and renal dysfunction. Metabolism 35, Supp 1, 46-54 (1986)

12 Tilton RG, Baier LD, Harlow JE, Smith SR, Ostrow E and Williamson JR: Diabetes-induced glomerular dysfunction: Links to a more reduced cytosolic ratio of $\mathrm{NADH} / \mathrm{NAD}^{+}$. Kidney Int 41, 778-788 (1992)

13 Geisen K, Utz R, Grotsch H, Lang HJ and Nimmesgern H: Sorbitol-accumulating pyrimidine derivatives. Arzneimittelforschung 44, $1032-1043$ (1994)

14 Terashima H, Hama K, Yamamoto R, Tsuboshima M, Kikkawa $R$, Hatanaka I and Shigeta $Y$ : Effect of a new aldose reductase inhibitor on various tissues in vitro. J Pharmacol Exp Ther 229, $226-230$ (1984)

15 Simard-Duquesne N, Greselin E, Dubuc J and Dvornik D: The effect of a new aldose reductase inhibitor (Tolrestat) in galactosemic and diabetic rats. Metabolism 34, 885-892 (1985)

16 Ao S, Shingu Y, Kikuchi C, Takano Y, Nomura K, Fujiwara T, Ohkubo $Y$, Notsu $Y$ and Yamaguchi I: Characterization of a novel aldose reductase inhibitor, FR74366, and its effects on diabetic cataract and neuropathy in the rat. Metabolism 40 , $77-87$ (1991)

17 Matsui $T$, Nakamura $\mathrm{Y}$, Ishikawa $\mathrm{H}$, Matsuura $\mathrm{A}$ and Kobayashi F: Pharmacological profiles of a novel aldose reductase inhibitor, SPR-210, and its effects on streptozotocin-induced diabetic rats. Jpn J Pharmacol 64, 115- 124 (1994)

18 Mizuno K, Kato N, Matsubara A, Nakano K and Kurono M: Effects of a new aldose reductase inhibitor, $(2 S, 4 S)$-6-fluoro$2^{\prime}, 5^{\prime}$-dioxospiro [chroman - 4, 4'-imidazolidine] - 2 -carboxamide (SNK-860), on the slowing of motor nerve conduction velocity and metabolic abnormalities in the peripheral nerve in acute streptozotocin-induced diabetic rats. Metabolism 41, $1081-1086$ (1992)

19 Clements RS Jr and Winegrad AI: Purification of alditol: NADP oxidoreductase from human placenta. Biol Biophys Res Commun 47, 1473-1479 (1972)

20 Vander Jagt DL, Hunsaker LA, Robinson B, Stangebye LA and Deck LM: Aldehyde and aldose reductases from human placenta. Heterogeneous expression of multiple enzyme forms. J Biol Chem 265, 10912-10918 (1990)

21 Bhatnagar A, Liu S, Das B, Ansari NH and Srivastava SK: Inhibition kinetics of human kidney aldose and aldehyde reductases by aldose reductase inhibitors. Biochem Pharmacol 39, $1115-1124$ (1990)

22 Bergmeyer HU, Gruber $\mathrm{W}$ and Gutmann I: D-Sorbitol. In Methods of Enzymatic Analysis (second edition), Edited by Bergmeyer HU, Vol 3, pp 1323-1330, Academic Press, Inc, New York (1974)

23 Miyoshi $\mathrm{T}$ and Goto 1: Serial in vivo determinations of nerve 
conduction velocity in rat tails. Physiological and pathological changes. Electroencephalogr Clin Neurophysiol 35, 125-131 (1973)

24 Ao S, Kikuchi C, Ono T and Notsu Y: Effect of instillation of aldose reductase inhibitor FR74366 on diabetic cataract. Invest Ophthalmol Vis Sci 32, 3078-3083 (1991)

25 Kador PF, Akagi $Y$ and Kinoshita JH: The effect of aldose reductase and its inhibition on sugar cataract formation. Metabolism 35, Supp 1, 15-19 (1986)

26 Chylack LT, Leske MC, Sperduto R, Khu P, McCarthy D and the Lens Opacities Case-Control Study Group: Lens opacities classification system. Arch Ophthalmol 106, 330-334 (1988)

27 Tao RV, Takahashi Y and Kador PF: Effect of aldose reductase inhibitors on naphthalene cataract formation in the rat. Invest Ophthalmol Vis Sci 32, 1630-1637 (1991)

28 Yamamoto $\mathrm{Y}$ and Ohtori A: In vitro study of aldose reductase inhibitor concentrations in the lens and inhibitory effect on sugar alcohol accumulation. Curr Eye Res 9, 421-428 (1990)

29 Ohtori A, Yamamoto Y and Tojo KJ: Penetration and binding of aldose-reductase inhibitors in the lens. Invest Ophthalmol Vis Sci 32, 189- 193 (1991)

30 Inukai $\mathrm{S}$, Agata $\mathrm{M}$, Sato $\mathrm{M}$, Naitou $\mathrm{A}$, Matsukawa $\mathrm{H}$ and Goto M: Characterization of a novel aldose reductase inhibitor, TAT, and its effects on streptozotocin-induced diabetic neuropathy in rats. Jpn J Pharmacol 61, 221-227 (1993)
31 Yasuda $\mathbf{H}$, Sonobe $M$, Yamashita M, Terada M, Hatanaka I, Huitian $Z$ and Shigeta $Y$ : Effect of prostaglandin $E 1$ analogue TFC612 on diabetic neuropathy in streptozocin-induced diabetic rats. Comparison with aldose reductase inhibitor ONO 2235. Diabetes 38, $832-838$ (1989)

32 Shindo $\mathrm{H}$, Tawata $\mathrm{M}$, Aida $\mathrm{K}$ and Onaya $\mathrm{T}$ : The role of a cyclic adenosine 3',5'-monophosphate and polyol metabolism in diabetic neuropathy. J Clin Endocrinol Metab 74, 393-398 (1992)

33 Beyer-Mears $A$ and Cruz E: Reversal of diabetic cataract by sorbinil, an aldose reductase inhibitor. Diabetes 34, 15-21 (1985)

$34 \mathrm{Hu}$ TS, Datiles $\mathrm{M}$ and Kinoshita JH: Reversal of galactose cataract with Sorbinil in rats. Invest Ophthalmol Vis Sci 24, $640-644$ (1983)

35 Kinoshita JH: Mechanisms initiating cataract formation. Invest Ophthalmol 13, 713-723 (1974)

36 Win $\mathrm{T}$, Asano $\mathrm{G}$ and Shimizu $\mathrm{Y}$ : The efficacy of aldose reductase inhibitor, antioxidant butylated hydroxytoluene and cysteine protease inhibitor E64 on hyperglycemia-induced metabolic changes in the organ-cultured bovine lens. J Nippon Med Sch 61, $180-189$ (1994)

37 Azuma M, Inoue E, Oka $\mathbf{T}$ and Shearer TR: Proteolysis by calpain is an underlying mechanism for formation of sugar cataract in rat lens. Curr Eye Res 14, $27-34$ (1995) 